\title{
Entre efemérides e histórias de grandes vultos: a presença das "trajetórias de vida" (biografias) nas aulas de História do Ensino Médio
}

\author{
Between Ephemerides and Stories of \\ Great Figures: The Presence of "Life Trajectories" \\ (Biographies) in History Classes of High School
}

Jerônimo Adelino Pereira Cisneiros Galvão*

\section{RESUMO}

O presente artigo discute o uso da biografia como recurso didático nas aulas de História do Ensino Médio. Para tal, partimos da análise do aporte teórico-metodológico da historiografia contemporânea sobre a escrita de biografias. Em seguida, passamos à discussão teórica acerca do ensino de História e da aprendizagem histórica, visando possibilidades de construção de saberes históricos a partir do uso de narrativas biográficas no Ensino Médio. Como resultado, problematizamos o uso deste recorte temático nesta etapa do ensino apontando possibilidades de emprego de histórias de vida em sala de aula na atualidade, dentro de um processo de ressignificação das mesmas.

Palavras-chave: ensino de História; aprendizagem histórica; biografias.

\section{ABSTRACT}

The present article discusses the use of biography as a didactic resource in History classes from High School. For this, we start from the analysis of the theoretical-methodological contribution of contemporary historiography on the writing of biographies. Then we move on to the theoretical discussion about the history teaching and historical learning, aiming at possibilities of building historical knowledge from the use of biographical narratives in high school. As a result, we problematize the use of this thematic excerpt at this stage of teaching pointing out possibilities of using life stories in the classroom today, within a process of reframing them.

Keywords: History teaching; historical learning; biographies.

O uso de biografias como recurso didático nas aulas de História não é algo novo. No Brasil, desde o surgimento das primeiras turmas de educação formal, encontra-se o uso de biografias nas práticas pedagógicas de professores e pro-

\footnotetext{
* Secretaria de Educação Pernambuco, Recife, PE, Brasil. jerosystem@hotmail.com
} 
fessoras. No entanto, o tipo de biografia utilizada nas aulas servia para explorar de maneira factual alguns eventos. E numa perspectiva heroicizante contava-se as histórias de vida como exemplos a serem internalizados pela sociedade. Nesse sentido, havia pouco espaço para a crítica histórica acerca de vidas que eram sacralizadas ou demonizadas. Personagens eram tomados da História para encarnar os valores de regimes políticos, sociedades e culturas, passando a ser os portadores de todas as virtudes. Nesse tipo de narrativa, aqueles que eram colocados como inimigos do regime em curso passavam a ser os portadores de todos os vícios. A narrativa didática em torno de trajetórias de vida no ensino de História era então baseada na história política de grandes vultos.

Esse modelo factual, heroico e exemplar, presente nas narrativas utilizadas nas escolas brasileiras desde o século XIX até a década de 1980, fez com que posteriormente não houvesse uma boa aceitação do trabalho com biografias como recurso didático entre os docentes. Nessa perspectiva, Kalina Vanderlei Silva afirma:

Não seria exagero afirmar que, hoje, muitos professores brasileiros sentiriam um calafrio só de pensar em utilizar biografias como tema de ensino. Isso porque, quando eles próprios estavam na escola, uma das formas de estudar História era decorar datas e fatos relacionados aos heróis nacionais. (PINSKY, 2010, p. 13)

Essa rejeição deve-se a diversos fatores. Dentre eles, o fato do Brasil, há algumas décadas, ter vivido a repressão, o obscurantismo e o negacionismo da pedagogia, instituídos pela ditadura civil-militar, quando estudar biografias em aulas de Moral e Cívica e de Estudos Sociais tornou-se sinônimo de cultuar a memória de figuras heroicizadas, representativas das chamadas virtudes de uma estrutura de poder autoritária e de uma ideologia nacionalista e ufanista. Com a redemocratização, muitos docentes passaram a rejeitar esse recorte temático, que passou a ser visto como característico de uma "história tradicional" de viés autoritário e factual. É necessário deixar claro, entretanto, que houve certa permanência de narrativas didáticas factuais e de biografias heroicas, tendo inclusive resquícios na atualidade. Paulatinamente, porém, a partir da rejeição de muitos professores a este recorte, o ensino escolar de História no Brasil foi se afastando de narrativas biográficas.

No processo de construção da Nova República, emerge a necessidade de superação do ensino de História "tradicional” por modelos que trabalhassem 
essa área de conhecimento de maneira crítica na escola. Nesse sentido, em meio ao processo de redemocratização, houve grande influência das universidades sobre o ensino de História escolar que voltava a ocorrer de maneira independente da disciplina Estudos Sociais. O paradigma estruturalista, ${ }^{1}$ hegemônico na academia brasileira na década de 1980, paulatinamente torna-se predominante nas narrativas didáticas das aulas de História. Apesar de algumas permanências de modelos de ensino de História mais tradicionais, estes foram se tornando, pouco a pouco, exceções. A biografia enquanto narrativa histórica anteriormente presente nas aulas de História foi rejeitada pelo novo modelo que se estabelecia. Diante desses fatos, a historiadora Kalina Silva continua sua argumentação em torno do uso de biografias nas aulas de História "[...] nem tudo o que é "velho" é necessariamente ruim. Se bem empregada, a biografia se torna um elemento a favor do professor dinâmico, que deseja despertar em seus alunos o interesse pela História e ajudá-los no processo de aquisição de conhecimento." (Ibidem).

As biografias desenvolvidas pela academia, na atualidade, não são construídas da mesma forma que em outros períodos. O estruturalismo nas Ciências Humanas passou a ser questionado, ainda na década de 1970, frente à crise do Estado de Bem-Estar Social; bem como as Revoluções Cultural e Social, que colocam outros elementos identitários que não a categoria classe social no centro dos debates políticos; além dos movimentos contrários ao autoritarismo do bloco socialista, no leste europeu. Nesse contexto, uma nova forma de perceber e escrever biografias começa a emergir. Nas últimas décadas, a escrita biográfica tomou parte do centro das discussões historiográficas, voltando com força total na escrita da História. Dentro de novos aportes teórico-metodológicos, com novos objetos e novos sujeitos a serem trabalhados. Esse novo contexto contempla não apenas as biografias históricas, mas também as narrativas biográficas ligadas a outras áreas do conhecimento. O que nos levou a questionar: como desenvolver processos de aprendizagem histórica no Ensino Médio a partir do trabalho com biografias?

Ao buscar responder a esse questionamento, levamos em consideração a legitimidade do temor de que velhos formatos biográficos apresentados como novos possam voltar às aulas de História. No entanto, se por um lado os antigos formatos biográficos nunca deixaram plenamente as salas de aula, por outro, a superação dessas narrativas obsoletas passa necessariamente pelo uso 
do recorte temático biográfico dentro de novos aportes teórico-metodológicos. Onde a narrativa biográfica seja trabalhada em sala de aula com o viés da História-Problema.

Dessa forma, o objetivo no presente artigo é analisar como o estudo de biografias, a partir do aporte teórico-metodológico da historiografia contemporânea, através da mediação docente no espaço escolar, pode contribuir para a construção de saberes históricos no Ensino Médio. Assim, estruturamos nossa reflexão em três seções. Na primeira, partimos do questionamento: é possível ensinar História através do trabalho com biografias? Para respondermos a essa indagação, utilizamos os conceitos de consciência histórica e cultura histórica inseridas no campo do Ensino de História. No segundo momento, questionamos: é possível aprender História através do estudo de biografias? Aqui utilizamos os conceitos de aprendizagem histórica e literacia histórica no sentido de analisarmos as possibilidades de aprendizagem de saberes históricos pelos educandos. Por fim, traçamos possíveis usos de biografias, onde partimos de uma discussão sobre o Ensino Médio e o componente curricular História, na atualidade. Além disso, refletimos acerca dos saberes e práticas no espaço escolar utilizando a teoria das operações historiográficas escolares, da ideia da aula como texto e das ricas possibilidades do trabalho com projetos tendo como recorte temático o uso de biografias.

\section{É POSSÍVEL ENSINAR HISTÓRIA ATRAVÉS DO TRABALHO COM BIOGRAFIAS?}

Entendemos aqui o ensino de História como essencialmente formativo, emancipador e libertador, tendo como finalidade um papel orientador através da consciência histórica. Selva G. Fonseca, em sua obra Didática e Prática de Ensino de História (2003), trata da dimensão essencialmente formativa da disciplina, no sentido de sua grande importância para a vida social em termos de construção da cidadania e da democracia. Nesse sentido, coloca a necessidade de diversificação de fontes e da dinamização da prática de ensino visando a democratização do acesso ao saber, através da possibilidade de debate entre diferentes visões, superando assim abordagens até então recorrentes no Ensino Fundamental e Médio.

Ainda segundo a autora, novas propostas de ensino de História emer- 
gem da atual produção historiográfica dando voz e lugar aos diferentes sujeitos históricos, desafiando modelos ideológicos homogeneizadores. A partir desse ponto, ela propõe que a pesquisa e a produção de conhecimentos façam parte da sala de aula. A autora não fala na utilização de biografias nas aulas de História. Contudo, o caminho é aberto no sentido de colocar que as questões debatidas nos cursos de graduação devam chegar ao ensino básico, mediadas pela ação pedagógica de professores que desenvolvam a pesquisa em termos de produção de conhecimentos em sala de aula. Em outras palavras, se temas biográficos têm ganhado espaço na academia, por que não levar essa temática à escola, dentro de seus novos aportes teórico-metodológicos e com seus novos sujeitos?

Segundo François Dosse (2015), vivenciamos atualmente a idade hermenêutica. Esta corresponde à revalorização da singularidade dentro das Ciências Humanas, que motivaram não só a retomada do interesse pela biografia como também sua transformação em um gênero mais reflexivo. $O$ perfil das biografias históricas atuais possibilita trabalhar saberes históricos em sua complexidade, fazendo com que as mesmas possam ser problematizadas em sala de aula. Esse novo perfil fica claro no estudo desenvolvido por Bourdieu (1996), onde o mesmo critica os formatos cronológicos e factuais de narrativas acerca de histórias de vida. A vida, como um conjunto coerente e orientado, vinculado a uma intenção subjetiva e objetiva de um projeto, não passaria de uma ilusão biográfica. $\mathrm{O}$ autor apresenta, assim, os sujeitos como fracionados e múltiplos, partes de um contexto no qual ocupam um conjunto de posições simultaneamente. A escrita de biografias no meio acadêmico atual é desenvolvida tendo-se em mente as profundas e produtivas críticas bourdieusianas.

A noção de biografia aqui utilizada dialoga com Dosse (2015), que situa o gênero biográfico em meio a uma tensão que se dá entre a ficção e a realidade histórica. Devido a essa tensão, que torna a biografia um gênero singular, perpassam pela escrita biográfica escritores de diferentes áreas, estilos e objetivos como jornalistas, historiadores, romancistas e políticos. Por outro lado, o conceito de biografia refere-se à narrativa ligada à história de vida de alguém. Nesse sentido, entendemos que deve-se inserir nessa discussão os relatos de vida e a autobiografia. Os três gêneros têm como base a história de vida individual, ou seja, a sequência narrativa biográfica (PEREIRA, 2000). Apesar de terem essa característica em comum, possuem também distinções, pois, en- 
quanto a biografia é a história de vida de alguém narrada por outro, o relato de vida e a autobiografia são autonarrações do sujeito. Ambas são permeadas pela memória, diferenciando-se entre si pela mediação do entrevistador no relato de trajetória de vida. Uma outra questão a ser considerada nesse sentido é que, quando apresentamos possibilidades do uso de biografias nas aulas de História, estas são biografias históricas, escritas por historiadores, que utilizam-se de uma problemática e de métodos desta área de conhecimento. A autobiografia e os relatos de vida, por sua vez, não são necessariamente escritas por profissionais da História.

A discussão em torno da mediação pedagógica do docente frente ao desafio de trabalhar biografias em sala de aula, diante dos novos olhares e sujeitos que emergem na historiografia atual, tem como referência autores como Jörn Rüsen, Peter Lee, Fernando Penna, Ilmar Mattos e Selva G. Fonseca. Trabalhamos aqui com os conceitos de Aprendizagem Histórica e Consciência Histórica, de Jörn Rüsen, além do conceito de Literacia Histórica desenvolvido por Peter Lee. De fato, o arcabouço conceitual desenvolvido pela Didática da História Alemã, cujo principal expoente é o Rüsen, e pela Educação Histórica Britânica, a qual filia-se Peter Lee, foram essenciais para a análise pedagógico-histórica da pertinência do uso de biografias como recurso para a construção de saberes e práticas no espaço escolar, no ensino de História.

A Teoria das Operações Historiográficas Escolares desenvolvida por Fernando Penna em sua tese de Doutorado Ensino de História: operação historiográfica escolar (2013) também foi essencial na construção do arcabouço teórico-metodológico para este trabalho. No mesmo sentido, Ilmar R. de Mattos, em seu artigo "Mas não somente assim! Leitores, autores, aulas como texto e o ensino-aprendizagem de história” (2007), desenvolve a ideia da aula de História como texto com autoria do professor. Ao ser posto em diálogo com a tese de Penna, acabou por levar-nos a garantir o desenho de nossa ação metodológica em torno da utilização das histórias de vida em sala de aula. Já Selva Guimarães Fonseca, em sua obra Didática e Prática de Ensino de História (2003), traz uma importante discussão em torno das práticas de ensino de História em sala de aula, apresentando possibilidades de trabalho inovadoras inteiramente válidas na atualidade.

Com relação à finalidade orientadora da História através da consciência histórica, podemos afirmar que esse instrumento conceitual aplica-se no sen- 
tido de que as ideias que possuímos sobre o passado e as aspirações que temos acerca do futuro participam ativamente de nossas ações e atitudes no presente. Para Jörn Rüsen, a consciência histórica é a “(...) soma das operações mentais com as quais os homens interpretam sua experienciada evolução temporal de seu mundo e de si mesmos de forma tal que possam orientar, intencionalmente, sua vida prática no tempo" (2001, p. 57).

O ser humano possui a incrível capacidade de refletir acerca do passado, bem como de planejar o futuro. Dessa forma, tanto o passado como o futuro participam ativamente do presente. Como atuamos na realidade a partir de projeções e intencionalidades, tudo que fazemos, buscamos fazer ou nos ocorre, passa por um processo de atribuição de sentido que depende diretamente da consciência histórica, tornando-a essencial na busca por um sentido existencial. A consciência histórica, dessa maneira, é um dado antropológico intrinsecamente vinculado à existência humana. Não é um saber adquirido através do conhecimento histórico acadêmico ou escolar, estes não possuem qualquer forma de monopólio acerca da formação da consciência histórica. A consciência histórica é um saber ligado à própria historicidade da vivência humana e a identidade das sociedades está diretamente vinculada à mesma (CERRI, 2011).

É preciso deixar claro que não se trata de pensar que a consciência histórica é algo que se tem ou não se tem, ou ainda que exista uma forma certa ou errada da mesma, baseando-se na utilização de determinados saberes históricos como a narrativa e a problematização de histórias de vida. Trata-se de entender que a consciência histórica pode ser mais ou menos aprofundada. A conscientização, dessa maneira, não seria uma doação de um sujeito para o outro; surgiria, porém, através do diálogo. Ao trabalhar com saberes históricos em sua complexidade e em vista das contradições presentes na realidade das temáticas a serem abordadas, abrimos espaço para a construção de processos de conscientização. Nesse sentido, há um interessante estudo desenvolvido por Itamar Freitas e Maria Margarida Dias de Oliveira (2016) onde os mesmos abordam a relação entre o ensino de História e a consciência crítica, explorando a obra de Paulo Freire e de Jörn Rüsen e traçando paralelos entre o que este categoriza como consciência histórica genética e o conceito de consciência crítica nas obras daquele. A consciência crítica freireana levaria o indivíduo ao autoconhecimento, onde o mesmo passaria a ser capaz de justificar sua exis- 
tência em tempos, espaços e circunstâncias. A consciência histórica genética, por sua vez, seria uma forma de construir a identidade individual e coletiva compatível com a realidade na qual se está inserido, tendo como base uma orientação que mobiliza para uma situação melhor que a do passado.

Como afirmamos, a ciência histórica e o ensino escolar de História não detêm o monopólio na forma de organização da consciência histórica de uma determinada sociedade. De fato, muito antes de lidar com qualquer cultura escolar, ${ }^{2}$ os indivíduos já estão mergulhados em culturas permeadas por diversas narrativas de historicidade. Essas narrativas históricas estão presentes nos meios de comunicação de massas, nas famílias, nas igrejas, enfim, no meio em que os estudantes vivenciam seu cotidiano. Daí surge a noção de cultura histórica. A cultura histórica deve ser entendida como uma categoria de análise que remete ao fenômeno do uso da memória no espaço público, ou seja, seria o conjunto de elementos estéticos, cognitivos e políticos associados à produção de sentidos e significados da relação presente/passado/futuro, em seus usos públicos e suas mais variadas manifestações (HAAS JR, 2017).

Narrativas biográficas ou histórias de vida de maneira geral fazem parte da cultura histórica de qualquer sociedade atual. Sejam elas desenvolvidas pelo meio acadêmico ou contadas entre pessoas que buscam uma instrumentalidade educativa exemplar, o fato é que elas participam também da constituição da consciência histórica da sociedade. Mesmo quando as biografias estiveram parcialmente afastadas do meio acadêmico devido à predominância de um pensamento estruturalista, elas não se ausentaram das conversas informais ou das obras cinematográficas e televisivas, nem das listas de obras mais vendidas nas livrarias.

A ciência histórica também faz parte da cultura histórica, ocupando, de certa forma, um lugar privilegiado nela devido a sua legitimidade, conferida pela operação historiográfica e pela própria sociedade que utiliza tal conhecimento como referencial verossímil acerca de seu passado. As biografias, enquanto elemento presente na cultura histórica, também podem e devem ser problematizadas pelo conhecimento histórico, tanto acadêmico como escolar. Com relação à academia, esse trabalho de ressignificação, problematização e retorno da narrativa biográfica vem ocorrendo nas últimas décadas com certo êxito. É necessário, porém, discutir essa questão também no ensino escolar de História. 
Com relação à importância de um conhecimento histórico sistematizado, para além da questão de sua legitimidade, é preciso também ressaltar o aspecto da necessidade de uma ciência histórica e de um ensino de História, em meio à cultura histórica. De fato, há sempre uma luta em torno do passado e da memória, onde muitas vezes grupos tentam legitimar suas práticas e pretensões a partir da fabricação de passados úteis aos seus propósitos, mesmo que inconsistentes diante de uma análise mais sólida dos indícios apresentados. Daí, surge a necessidade de um conhecimento que sistematize e desenvolva a crítica em torno do estudo dos indícios que remetem ao passado para que este não seja usado e manipulado em benefício de determinado grupo. É preciso ter consciência de que existem relações de poder presentes no processo de criação de referenciais históricos de identificação, como demonstrado por Eric Hobsbawm e Terence Ranger em sua obra A Invenção das Tradições (2008). Assim, o ensino de História, em todos os níveis do aprendizado, deve atuar também no sentido de revelar esse fato através da problematização do passado. O estudo de biografias em aulas de História, nesse sentido, deve necessariamente seguir uma linha baseada na problematização histórica.

Se a biografia deixa de fazer parte, em grande medida, do ensino de História escolar, nem por isso ela vai desaparecer da cultura histórica, muito pelo contrário, ela estará lá, tendo sua narrativa formulada por outros agentes. Se vez ou outra a narrativa biográfica que aparece na sala de aula for a versão exemplar e/ou heroica dos personagens - e o problema desse formato é que o mesmo não possui a devida problematização e crítica histórica -, isso precisa ser problematizado em sala de aula. É preciso que o tema biográfico seja rediscutido e atualizado nesse espaço. Se essas questões não forem discutidas nas aulas de história, onde serão? Como os cidadãos serão capazes de problematizar uma história de vida? Apenas através da produção historiográfica acadêmica? Se alguém porventura acreditar que isso seja uma possibilidade razoável, é importante lembrar que atualmente a cultura de leitura no Brasil não é das melhores.

Para além dos novos aportes teórico-metodológicos e dos novos sujeitos é importante também afirmar que a escrita de biografias por historiadores é história. A escrita da biografia histórica, assim como qualquer outra temática neste campo, perpassa a necessidade de um problema de pesquisa histórico desenvolvido a partir de referências conceituais e fontes ligadas a pesquisa 
desse campo de estudos (CARDOZO e VAINFAS, 2012, p. 195). Nesse sentido, a discussão acerca do recorte temático biográfico e a problematização de biografias não pode ser deixada à margem no ensino de História escolar.

Se a consciência histórica, de forma geral, possui um caráter orientador, podemos inferir que a orientação da práxis humana torna-se um dos fundamentos da ciência histórica. Sendo assim, toda narrativa histórica constitui uma resposta a carências e necessidades práticas dos seres humanos. $\mathrm{O}$ trabalho dos historiadores na escrita da História, dessa forma, possui sempre um caráter didático. A escrita de biografias também, pois, sendo escritas ou não por historiadores, fazem parte da cultura histórica na qual são produzidas. Tenham os biógrafos consciência disso ou não.

Como as biografias fazem parte da cultura histórica, participando da consciência histórica das sociedades, existem não apenas possibilidades de trabalho no ensino de História com as mesmas, mas há a necessidade desse tipo de trabalho. Entendendo o ensino de História como formativo, é necessário que aqueles que aprendem História aprendam a trabalhar com a leitura de sequências biográficas, para que possam desenvolver ferramentas que os levem a problematizar e desnaturalizar histórias de vida por meio da crítica histórica.

É POSSÍVEL APRENDER HISTÓRIA ATRAVÉS

DO ESTUDO DE BIOGRAFIAS?

Apesar de havermos discutido as possibilidades do ensino de História através do trabalho com biografias, a grande finalidade a ser atingida tanto através da produção do conhecimento histórico, como do ensino de História, é, sem sombra de dúvidas, a aprendizagem. A aprendizagem é o grande astro no processo educativo. A verdadeira finalidade da produção de conhecimento. Já dizia Aristóteles na Antiguidade: "ensinar não é uma função vital, por que não tem o fim em si mesma, a função vital é aprender” (apud MATTOS, 2007, p. 14).

$\mathrm{O}$ que seria, entretanto, aprendizagem histórica? Como podemos definir um processo de aprendizagem na área da História? Jörn Rüsen coloca o aprendizado histórico como: 
[...] processo da consciência que se dá entre dois pontos de referência seguintes. De um lado, um dado objetivo de mudança temporal do homem e de seu mundo no passado. De outro, um sujeito determinado, uma autocompreensão e uma orientação de vida no tempo. O aprendizado histórico caracteriza-se, pois, como um movimento duplo: algo objetivo torna-se subjetivo, um conteúdo da experiência de ocorrências temporais é apropriado; simultaneamente, um sujeito confronta-se com essa experiência, que se objetiva nele. (2007, p. 106)

Além disso, Rüsen estabelece três dimensões de aprendizado histórico. A primeira diz respeito ao aumento da experiência voltada para a vida, a segunda relaciona-se com o aumento da competência interpretativa da realidade e a terceira trata da competência de orientação na vida prática. As três dimensões estão indissociavelmente interligadas, pois "não há experiência histórica livre de interpretação, nem orientação histórica livre de experiência” (Ibidem, p. 118).

Dessa forma, é possível perceber que a aprendizagem histórica, enquanto espaço de construção de saberes históricos, perpassa a formação da identidade, subjetividade e interpretação dos sujeitos. Sendo assim, entendemos que a aprendizagem histórica passa pela questão conceitual, mas também por uma formação atitudinal a partir da construção de sentidos históricos que se relacionam a orientação da própria vida. O processo de aprendizagem histórica ocorre por meio do gerenciamento do fenômeno pelo qual saberes históricos são colocados em relação, ampliados e modificados através do diálogo, envolvendo questões pedagógicas, éticas, morais e até mesmo existenciais. Assim, afirmou-se que "o sujeito estudante precisa assenhorear-se de si próprio a partir da história, formando sua identidade, sua subjetividade e sua interpretação" (CUNHA e CARDOZO, 2015, p. 542).

A história precisa ser significativa para o educando inclusive em termos pessoais, pois aprender história não é simplesmente construir conhecimentos sobre o passado, é também desenvolver competências da consciência histórica "necessárias para resolver problemas práticos de orientação com auxílio do saber histórico" (RÜSEN, 2007, p. 94). Ao aprender história, o estudante passa a lidar com saberes históricos em sua vida prática. O que significa, entretanto, possuir algum saber histórico? Para responder a esse questionamento adotamos o conceito de literacia histórica, desenvolvido por Peter Lee, que refere-se à "leitura de mundo" possibilitada pelo conhecimento histórico. Este pode ser interpretado como um conjunto de competências relacionadas à 
compreensão e interpretação do passado vinculadas a uma natureza transformativa da história frente à visão de mundo dos indivíduos e sociedades. Neste sentido, "a obtenção de literacia histórica potencialmente transforma a visão de mundo de crianças (e de adultos) e permite ações até então - literalmente - inconcebíveis para eles" (LEE, 2016, p. 108).

Conhecer algo da História pressupõe algumas condições como: compreender a história enquanto uma forma de ver o mundo, muitas vezes contraintuitiva; adquirir disposições que derivam e impulsionam a compreensão histórica; desenvolver imagens do passado que permitam a orientação no tempo. A aprendizagem ocorre de forma concreta. Assim, torna-se necessário que os conceitos façam sentido para quem vai aprendê-los. Dessa forma, conforme afirmou Barca, "existe uma multiplicidade de factores da cognição a ter em conta. As vivências prévias dos sujeitos e a natureza específica do conhecimento, o tipo de tarefas a desempenhar, as aptidões individuais são aspectos fundamentais para a progressão do conhecimento" (2001, p. 20).

Como desenvolver através do ensino de História um processo de aprendizagem histórica em sala de aula? Flávia E. Caimi (2015) discute, nessa questão, as demandas do trabalho do professor de História diante da complexidade e multiplicidade da escola atual, chegando à conclusão de que para ensinar História a alguém é preciso entender de ensinar, de história e desse alguém. Em outras palavras, para que o ensino de História torne-se significativo e envolvente aproximando-se dos interesses dos jovens, é necessário que se conheça não apenas os saberes a ensinar e para ensinar, mais também os saberes do aprender que se referem ao estudante.

Tendo sido discutido o que é aprendizagem histórica e como a mesma se processa na prática, é chegado o momento de levantamos a questão central: Como desenvolver aprendizagem de saberes históricos em sala de aula, na atualidade, a partir do trabalho com biografias? Trabalhar com biografias na sala de aula possibilita a compreensão das estratégias individuais dentro da complexidade dos elementos em jogo em um determinado contexto, inclusive quando são trabalhadas biografias de pessoas consideradas comuns. Esse tipo de abordagem em sala de aula possibilita a produção de questionamentos históricos a partir de pontos que não seriam possíveis por meio de outros lugares/ espaços históricos.

O trabalho com sequências biográficas, dentro de seus novos aportes te- 
órico-metodológicos, seguindo um viés de História-Problema, possibilita mediar em sala de aula processos de aumento da competência interpretativa da realidade e da orientação na vida prática. Há a possibilidade ainda de desenvolvimento de formas de leitura do mundo transformadoras de concepções e noções pré-concebidas sobre personagens e contextos históricos. Em outras palavras, é possível o aprofundamento da consciência histórica e a obtenção de literacia histórica a partir do estudo com histórias de vida. Afirmamos assim a possibilidade de construção de saberes históricos por meio do estudo de biografias.

Além disso, estudos com base no campo biográfico possibilitam a humanização da explicação histórica, no sentido de que sujeitos estariam dando materialidade a estruturas e contextos maiores. Ao invés de termos como sujeitos da narrativa histórica apenas estruturas, estatísticas e números, teríamos também pessoas. Uma aula que trate das guerras mundiais ressaltando apenas os números e as transformações geopolíticas soa diferente de uma aula sobre o mesmo assunto apresentando o soldado que estava no front ou a moça que passou a trabalhar na indústria bélica. Na segunda possibilidade corporifica-se a história através daqueles que a vivenciaram. A produção de sentidos se torna mais aproximada da vivência cotidiana dos discentes. Esse processo pode produzir, além da aprendizagem conceitual, uma formação atitudinal ligada ao autoconhecimento e reconhecimento dos educandos sobre seu papel de sujeitos da história.

\section{USOS DE BIOGRAFIAS NAS AULAS DE HISTÓRIA DO ENSINO MÉDIO}

O Ensino Médio no Brasil constitui-se historicamente como um campo de disputas. Por outro lado, como última etapa da Educação Básica, o mesmo apresenta uma série de peculiaridades ligadas a condicionamentos internos e externos que o singulariza frente a outros níveis do Ensino Básico. Apesar da busca pela resolução de problemas como a evasão escolar e o desinteresse dos educandos, desenvolvidas por meio de ações do Estado ou dos profissionais da Educação, um fato observado por Maria Auxiliadora M. Santos Schmidt (2015) é o desinteresse de muitos jovens estudantes do Ensino Médio frente aos conteúdos de História.

Segundo Volpi e Silva, "está claro que o ensino médio precisa ter um 
programa pedagógico afinado com as necessidades e os projetos de vida dos adolescentes, para que eles enxerguem valor na escola e se sintam estimulados a concluir seus estudos na educação básica." (VOLPI e SILVA, 2014). A observação desenvolvida como um desafio para o Ensino Médio no Brasil também deve aplicar-se ao ensino de História. De forma geral, é necessário que este faça sentido para a vida do educando fora dos muros da escola, inclusive em seu cotidiano. Como pudemos analisar ao longo deste artigo, o uso de biografias possibilita a construção de diferentes saberes históricos vinculando-se mesmo ao aprofundamento da consciência histórica e a processos de literacia histórica em sala de aula.

Se, como afirmam Mário Volpi e Maria de Salete Silva, é preciso um programa afinado com as necessidades e projetos de vida dos adolescentes para o avanço do Ensino Médio, apresentamos possibilidades de trabalho com histórias de vida como um dos muitos caminhos possíveis para aproximar os conteúdos das aulas de História do cotidiano dos educandos, ao mesmo tempo que apresentamos possibilidades de autorreconhecimento dos mesmos enquanto sujeitos históricos a partir do trabalho com essa temática.

De fato, trabalhar com abordagens biográficas no ensino de História escolar, tratando-as sob o viés de uma História-Problema, além de possibilitar a construção de saberes voltados para o autorreconhecimento do corpo discente enquanto sujeito da História, combate também o problema do discurso único. Esse tipo de discurso é problemático por diversos motivos, dentre os quais destaca-se a questão do desenvolvimento de estereótipos. Se trabalhamos em sala de aula, por exemplo, a questão das relações de gênero no Brasil Colonial dentro de um viés estruturalista, a explicação dá-se de uma determinada forma, percorrendo determinados caminhos lógicos. Se, diferentemente, apresentarmos mulheres que não se encaixavam nos padrões tidos como os mais comuns em determinado período, biografias de mulheres que se rebelaram contra os papéis a elas impostos pela sociedade da época, a história ganha novos contornos em sala de aula.

A personagem em questão nem precisa obrigatoriamente ser um caso excepcional normal, ${ }^{3}$ de alguma figura que fugiu dos padrões, rebelando-se contra eles abertamente. Mesmo se decidirmos trabalhar com a biografia de uma pessoa "típica", seguidora dos padrões sociais usuais no período, podemos também elucidar estratégias individuais de ação e reação dentro de determi- 
nada realidade social - fugindo, dessa maneira, da noção de passividade dos indivíduos frente aos contextos. Há espaço para trabalharmos com personagens que vão desde a Chica da Silva, de Júnia F. Furtado (2003), abordando as tramas na busca pela ascensão social da mulher negra em uma sociedade patriarcal e escravista, até personagens desconhecidas do grande público, como a vendeira Cândida Maria da Conceição, na sua luta por autonomia na província de Pernambuco sob o Império, como nos conta Maciel H. Silva (2011, p. 105-129). Podemos evidenciar inclusive micro-resistências individuais e coletivas no cotidiano que poderiam gerar a percepção de que a passividade de sujeitos da História frente à realidade é um mito, desenvolvido, muitas vezes, por aqueles que não querem fazer tal grupo aparecer como protagonista de sua própria história.

Além da apresentação de novos sujeitos/biografias que produzam novos pontos de vista e novos questionamentos históricos a serem trabalhadas nas aulas de História do Ensino Médio, faz-se necessário também revisitar e problematizar biografias de sujeitos que já circulam há algum tempo nas narrativas históricas escolares, como por exemplo o personagem Domingos Fernandes Calabar. Apesar do mesmo ter sido um senhor de engenho luso-brasileiro durante a ocupação de Pernambuco pelos holandeses no século XVII, tornou-se apoiador dos flamengos, passando a lutar contra as forças portuguesas. A partir deste fato, passou a ter sua biografia atrelada à ideia de que seria o maior de todos os traidores da pátria brasileira. Os argumentos dessa narrativa, porém, não resistem à menor crítica histórica. Se problematizarmos, por exemplo, se já havia uma pátria brasileira na época ou se o conceito está sendo utilizado de forma anacrônica, a resposta que obteríamos é que uma noção de nação brasileira como temos atualmente só vai emergir aproximadamente duzentos anos após os eventos relacionados à ocupação holandesa e ao personagem em questão. Como então ele poderia ser o traidor de algo que ainda não existia? Este é apenas um exemplo de como o uso das novas perspectivas historiográficas podem levar à construção de saberes históricos a partir do uso do recorte temático biográfico como recurso didático no Ensino Médio.

Como o professor de História poderia operacionalizar esse recurso temático em sua prática? O professor opera a partir de saberes docentes, valores culturais e políticos. Adotamos aqui a noção de saber apresentada por Tardif (2012), que coloca-se para além da dicotomia entre objetividade (conhecimen- 
to) e subjetividade (saber). De forma que entendemos o saber como elemento que se desenvolve em uma dimensão intersubjetiva. A argumentação enquanto dimensão intersubjetiva é um elemento privilegiado nessa concepção de saber. A vantagem dessa proposta reside no fato de que não há imposição aos saberes de um modelo limitado à abordagem científica. $\mathrm{O}$ que é racional (ou deixa de ser) não está posto a priori, porém desenvolve-se de acordo com os próprios atores envolvidos no processo argumentativo, estando o saber indissociavelmente ligado à ação e à interação com o outro.

O professor de História não opera no vazio, mas a partir de um conjunto de saberes. Utilizando-se destes, o docente pode, no processo de ensino e aprendizagem, trabalhar as histórias de vida como instrumento de potencialização e/ou construção de saberes históricos junto aos educandos. Na efetivação desses processos de construção de aprendizagem histórica é necessário o desenvolvimento da explicação histórica pelo docente. Essa explicação pode - e, a nosso ver, deve - levar ao desenvolvimento da produção de um conhecimento histórico em uma versão local, ligada ao ensino de História em sala de aula, adaptada às especificidades de cada turma, de acordo com suas características. Esse tipo de explicação histórica com autoria do professor leva ao que Mattos (2007) chama de aula como texto.

A partir da sentença de François Furet, "fazer história é contar uma história” (apud MATTOS, 2007, p. 7), Ilmar R. Mattos desenvolve o argumento de que na aula também se conta uma história. Uma aula de História não se desenvolve meramente seguindo-se currículos, materiais didáticos, ou qualquer outro material externo à aula em si. O professor de História se torna autor à medida que dá aula e essa aula ganha características de um texto original por meio da explicação histórica.

De modo categórico, afirmamos ainda uma vez que, por meio de uma aula, também se conta uma história; que, ao se contar uma história por meio de aula, também se faz história; e que somente ao se fazer história por meio de uma aula nos tornamos professores de história. Por lermos de um modo singular uma proposição, podemos afirmar que também somos autores. (Ibidem. p. 11)

O processo de desenvolvimento da aula como texto perpassa, a nosso ver, a teoria da operação historiográfica escolar, desenvolvida por Fernando Penna. Este desenvolve sua teoria através da articulação entre a ideia da transposição 
didática de Chevallard; às reflexões teóricas acerca da operação historiográfica de Certeau e Ricoeur e à teoria da argumentação presente em Perelman e Olbrechts-Tyteca. Uma operação historiográfica escolar corresponde a uma ação voltada para a construção de conhecimento histórico escolar, por meio da explicação histórica do professor. É preciso, entretanto, compreender que há dinâmicas presentes no trabalho com saberes históricos em sala de aula compreensíveis apenas a partir dos aportes da Educação, pois “a explicação histórica no ensino de história escolar não tem os mesmos objetivos e não segue as mesmas regras do conhecimento histórico produzido na academia" (PENNA, 2013, p. 219).

Entendemos que a aula como texto é o caminho a se seguir no processo de efetivação da construção de saberes históricos a partir da utilização de biografias, pois uma aula de História nunca será mera repetição de algum material historiográfico ou mesmo do material didático consultado pelo professor.

Se há riquíssimas possibilidades de trabalho nas aulas de História com biografias, o mesmo se aplica às autobiografias e aos relatos de vida que também trabalham com narrativas baseadas na sequência biográfica. Nessas narrativas acerca de histórias de vida, porém, a memória adquire certa centralidade. Ao se trabalhar com autobiografias e/ou com relatos de vida, é importante lidar previamente com a questão da memória em sala de aula, para que a necessária crítica e problematização dessas formas de sequência biográfica possa ser efetivada de maneira histórica. Da mesma forma que a crítica histórica é operada sobre textos, documentos e quaisquer outras fontes ligadas ao estudo da História, isso não é diferente quando trabalhamos historicamente com a memória, ou com projetos que levem em conta a História Oral, como no caso dos relatos de vida. É preciso estar atento à crítica histórica para que não se cristalize um passado baseado em memórias individuais.

Para além de operações didáticas que levem em consideração a operação historiográfica escolar e a aula como texto, existem ricas possibilidades de trabalho com as sequências biográficas por meio de projetos. O modelo de projeto proposto por Selva G. Fonseca, segue duas premissas básicas, sendo a primeira um trabalho intencional, desejado e compreendido pelo educando, e a segunda o entendimento de que todo projeto pressupõe uma produção, enquanto conjunto de tarefas necessárias a ser empreendida pelos educandos sob orientação do docente (2003, p. 109). Constitui-se em três fases distintas. A 
primeira correspondendo a identificação e formulação do problema, que engloba as discussões, planejamento, elaboração do projeto e formação dos grupos. A segunda fase relaciona-se com a construção e desenvolvimento do trabalho. A terceira, por sua vez, seria a fase da apresentação e socialização dos saberes produzidos. Concordamos com a autora quando afirma que "a realização de projetos requer pensar o saber histórico como algo que está sempre em construção, que tem a ver com o presente, não menosprezando as teorias e os conhecimentos históricos produzidos" (Ibidem., p. 123).

O ensino aqui não é somado às atividades do projeto. Pelo contrário, é pensado como processo permanente de investigação e de descobertas individuais e coletivas. Em suma, a pesquisa não é algo à parte da aula ou da aprendizagem escolar. É pensada como parte do processo de ensino-aprendizagem na escola. O trabalho por meio de projetos na Educação Básica constitui uma forma de reconciliar ação prática com construção de saberes. Apresenta-se como elemento ligado a uma operação historiográfica escolar efetiva, dentro do que é proposto por Fernando Penna (2013).

\section{CONSIDERAÇÕES FINAIS}

A utilização de biografias como recurso didático, em seus renovados aportes teórico-metodológicos nas aulas de História do Ensino Médio, dialoga fundamentalmente com a construção de alguns saberes históricos, como: a percepção de diferentes lugares de produção do discurso histórico, por meio da explicação histórica, em contraste com uma perspectiva apenas estruturalista; o autorreconhecimento dos discentes enquanto sujeitos da história; a interlocução necessária entre o conhecimento histórico escolar e o cotidiano; além de fecundas possibilidades de elaboração de projetos interdisciplinares, em virtude das biografias serem um gênero de fronteira.

As problemáticas em torno do uso e da escrita de biografias têm sido abordadas na historiografia contemporânea no Brasil e no mundo. O que propomos é trazer a discussão, com seus aportes teórico-metodológicos contemporâneos, para o espaço escolar, nas aulas de História. É preciso, no entanto, deixar claro que não estamos aqui propondo a eliminação das explicações estruturalistas, colocando, em seu lugar, explicações que tratem da História a partir de pontos singulares. Muito pelo contrário, o que estamos propondo é 
que não haja a hegemonia de nenhum formato explicativo nas aulas, mas que haja espaço também para as pessoas aparecerem como sujeitas da história.

É preciso deixar claro que não defendemos aqui uma volta ao ensino factual, heroico e moralizante de biografias, com grandes vultos a personificarem algo. Os procedimentos de pesquisa, a problematização e as formas narrativas de biografias históricas atualmente as configura como História, como nos adverte Benito Schmidt (2015). Aqui apresentamos essa categoria de biografias baseadas em uma História-Problema enquanto recurso didático para a construção e/ou potencialização de saberes históricos no Ensino Médio.

Apesar das inúmeras possibilidades de desenvolvimento de saberes e práticas no espaço escolar por meio do uso de sequências biográficas como recurso didático, há, contudo, especificidades na autobiografia e nos relatos de vida que fazem desses gêneros muito mais do que subgêneros da escrita biográfica. Não focalizamos, neste artigo, as especificidades destes gêneros em torno da memória e da História Oral. No entanto, deixamos aqui a percepção da necessidade de um aprofundamento maior acerca dessas duas áreas a serem trabalhadas em sala de aula, que aqui foram apresentadas como formatos narrativos relacionados ao gênero biográfico, por se basearem na sequência biográfica.

\section{REFERÊNCIAS}

BARCA, Isabel. Educação Histórica: uma nova área de investigação. Revista da Faculdade de Letras. História, Porto, v.2, n. 1, p. 13-21, 2001.

BOURDIEU, Pierre. A ilusão biográfica. In: AMADO, Janaina; FERREIRA, Marieta M. (Orgs.). Usos e Abusos da História Oral. Rio de Janeiro: Fundação Getúlio Vargas, 1996.

CAIMI, Flávia Heloísa. O que precisa saber um professor de história? História \& Ensino, Londrina, v. 21, n. 2. p. 105-124, 2015.

CERRI, Luís Fernando. Ensino de História e Consciência Histórica: implicações didáticas de uma discussão contemporânea. Rio de Janeiro: FGV, 2011.

CHERVEL, André. História das Disciplinas Escolares: reflexões sobre um campo de pesquisa. Teoria \& Educação, Porto Alegre, n. 02. 1990. p.177-229.

CUNHA, Jorge Luiz da; CARDOZO, Lisliane dos Santos. Os sentidos do trabalho do professor e o lugar social do ensino de História. Educação, Santa Maria, v. 40, n. 3 , p. 529-544, 2015. 
DOSSE, François. O Desafio Biográfico: escrever uma vida. Tradução: Gilson César Cardoso de Souza. 2aed. São Paulo: Edusp, 2015.

FONSECA, Selva Guimarães. Didática e Prática de Ensino de História. Campinas: Papirus, 2003.

FREITAS, Itamar; OLIVEIRA, Maria Margarida Dias de. Ensino de História e Formação da Consciência Crítica. In: MOLINA, Ana Heloísa; FERREIRA, Carlos Augusto Lima (Orgs.). Entre Textos e Contextos: caminhos no ensino de história. Curitiba: CRV, 2016, p. 471-480.

FURTADO, Júnia Ferreira. Chica da Silva e o Contratador dos Diamantes: o outro lado do mito. São Paulo: Companhia das Letras, 2003.

HAAS JÚNIOR, Arnaldo. História, Aprendizagem Histórica e o Ensino Médio: reflexões sobre (im)possibilidades da Educação Histórica no confronto com a cultura escolar. Tese (Doutorado em História Cultural). CFH/UFSC. Florianópolis, 2017.

HOBSBAWM, Eric. RANGER, Terence. A Invenção das Tradições. Tradução: Celina Cardim Cavalcante. $6^{\mathrm{a}}$ ed. Rio de Janeiro: Paz e Terra, 2008.

LEE, Peter. Literacia histórica e história transformativa. Educar em Revista, Curitiba, v.32, n. 60, p. 107-146, 2016.

MATTOS, Ilmar Rohloff de. "Mas não somente assim! Leitores, autores, aulas como texto e o ensino-aprendizagem de História". Tempo, Niterói, vol.11, n. 21, p. 5-16, 2007.

PENNA, Fernando de Araujo. Ensino de História: operação historiográfica escolar. Tese (Doutorado em Educação). Faculdade de Educação, UFRJ. Rio de Janeiro, 2013. Disponível em: https://ppge.educacao.ufrj.br/tpenna.pdf. Acesso em: 05 jul.2020.

PEREIRA, Lígia Maria Leite. Algumas reflexões sobre histórias de vida, biografias e autobiografias. História Oral, v.3, n. 3, 2000, p. 117-127.

RÜSEN, Jörn. Razão Histórica: teoria da história: fundamentos da ciência histórica. Tradução: Estevão de Rezende Martins. Brasília: Ed. Universidade de Brasília, 2001.

RÜSEN, Jörn. História Viva: teoria da história: formas e funções do conhecimento histórico. Tradução: Estevão de Rezende Martins. Brasília: Ed. Universidade de Brasília, 2007.

SCHMIDT, Benito Bisso. História e Biografia. In: CARDOZO, Ciro Flamarion; VAINFAS, Ronaldo (Orgs.) Novos Domínios da História. Rio de Janeiro: Elsevier, 2012. p. 187-205.

SCHMIDT, Maria Auxiliadora M. Santos. Formação da consciência histórica ou desenvolvimento de competências? Considerações sobre o ensino de história para jovens brasileiros. Diálogos, Maringá, v. 19, n.1, p. 87-116, 2015. 
SILVA, Kalina Vanderlei. Biografias. In: PINSKY, Carla Bassanezi (Org.) Novos Temas nas Aulas de História. São Paulo: Contexto, 2010, p. 13-28.

SILVA, Maciel Henrique. Pretas de Honra: vida e trabalho de domésticas e vendedoras no Recife do Século XIX (1840-1870). Recife/Salvador: EDUFPE-EDUFBA, 2011.

TARDIF, Maurice. Saberes Docentes e Formação Profissional. Tradução: Francisco Pereira. 14aed. Petrópolis: Vozes, 2012.

VOLPI, Mário; SILVA, Maria de Salete (orgs). 10 Desafios do Ensino Médio no Brasil: para garantir o direito de aprender de adolescentes de 15 a 17 anos. Brasília: UNICEF, 2014.

\section{NOTAS}

${ }^{1}$ Entendemos por paradigma estruturalista um conjunto de perspectivas, que emergem em meio as Ciências Humanas, ainda no século XIX, priorizando o estudo das estruturas em detrimento das singularidades. O indivíduo passa a ter um peso mínimo ou nulo na explicação dos grandes processos históricos. Originalmente presente em escolas de pensamento como o Positivismo e o Marxismo, esse paradigma consolidou-se no campo historiográfico com a Escola dos Annales, principalmente em sua segunda geração, com estudos que priorizavam a análise das estruturas que, independentemente dos indivíduos, comandavam a economia e a sociedade, além da política, cultura e mentalidades, como demonstrado por François Dosse (2015).

${ }^{2}$ Estudos sobre cultura escolar começam a surgir na década de 1980, ganhando força na década de 1990, tendo em comum a concepção de que a escola é portadora de práticas, noções e valores que a diferencia de outras instituições sociais. André Chervel, nesse sentido, entende que a escola produz uma cultura específica, original e singular, não devendo ser vista meramente como local de difusão de saberes construídos em outras instituições, como as universidades (CHERVEL, 1990).

${ }^{3}$ A categoria de análise excepcional normal, desenvolvida pelo historiador italiano Edoardo Grendi, vincula-se ao método da micro-história. Trata-se de uma ferramenta para análise de documentos tidos como excepcionais por darem voz a grupos que desenvolvem variadas formas de resistência contra crenças e comportamentos da maioria.

Artigo recebido em 29 de agosto de 2020. Aprovado em 14 de outubro de 2020. 